\title{
Selective Reduction of Multifetal Pregnancy
}

National Cancer Institute

\section{Source}

National Cancer Institute. Selective Reduction of Multifetal Pregnancy. NCI Thesaurus.

Code C117317.

A medical procedure performed to reduce the number of viable fetuses. 